\title{
Secondary prevention for patients after a myocardial infarction: summary of NICE guidance
}

Clarification-This NICE guideline summary (BMJ

2007;334:1112, doi:10.1136/bmj.39204.531586.AD) has now

been superseded by a summary of updated guidance at www.

bmj.com/content/347/bmj.f6544.
Cite this as: BMJ 2013;347:f6923

๑ BMJ Publishing Group Ltd 2013 